\title{
Hypericum perforutum and Vitamin B6 as a Treatment for Premenstrual Syndrome
}

\author{
Masumeh Ghazanfarpour, Somayeh Abdolahian, ${ }^{2}$ Talat Khadivzadeh, ${ }^{3}$ and Masoomeh Kaviani ${ }^{1,}$ \\ ${ }^{1}$ Fatemeh College of Nursing and Midwifery, Shiraz University of Medical Sciences, Shiraz, IR Iran \\ ${ }^{2}$ Department of Midwifery, Islamic Azad University, Firuzabad, Fars, Iran \\ ${ }^{3}$ Department of Midwifery, School of Nursing and Midwifery, Mashhad University of Medical Sciences, Mashhad, Iran \\ "Corresponding author: Masoomeh Kaviani, Fatemeh College of Nursing and Midwifery, Shiraz University of Medical Sciences, Shiraz, IR Iran. Tel: +98-9136330656, E-mail: \\ ghazanfarpm901@mums.ac.ir
}

Received 2015 October 27; Revised 2016 August 30; Accepted 2016 September 18.

\begin{abstract}
Background: It is shown that the premenstrual syndrome is related to a plethora of problems due to its direct and indirect effects on work, school, home, and productivity or inefficiency of relationships with others.

Methods: A double-blind, randomized controlled clinical trial (RCTs) was conducted in gynecology clinic of Zeinabieh Hospital affiliated to Shiraz University of Medical Sciences. Two hundred and thirty eight patients with premenstrual syndrome participated in the study. The prospective menstrual daily (MD) were filled by patients two months prior to the intervention. Then, they were randomly allocated into three groups: one group received two Hypericum perforutum tablets containing $330 \mu$ g hypericin; the second group received two vitamin B6 tablets containing $40 \mathrm{mg}$ of vitamin B6, and the third group took two placebo tablets daily from the first to 30 th day of menstrual cycle for two cycles.

Results: The mean total score decreased from $34.47 \pm 6.82$ to $20.68 \pm 5.72(40 \%)$ in the perforan group, from $33.93 \pm 6.95$ to 20.92 \pm 5.26 (38\%) in the vitamin B6 and from $33.86 \pm 6.16$ to $23.90 \pm 6$ (29\%) in the control group. The mean total score demonstrated a statistically significant decrease in the three arms compared to the baseline $(\mathrm{P}<0.001)$. Also, the comparison of the three groups showed a significant difference at terminal weeks $(\mathrm{P}<0.002)$.

Conclusions: Hypericum perforutum and vitamin B6 are safe, well tolerated and effective drugs to treat females with moderate to severe premenstrual syndrome in Iran.
\end{abstract}

Keywords: Hypericum perforutum, Vitamin B6, Premenstrual Syndrome

\section{Background}

Premenstrual syndrome (PMS) is characterized by a clustering of symptoms, both emotional and physiological, occurring in the week prior to the menstruation and disappearing a week after the initiation of menses (1-3). Premenstrual symptoms occur in 30\% - 80\% of the females of reproductive age, $3 \%-8 \%$ of females with the diagnostic criteria of a severe form of PMS called premenstrual dysphoric disorder (PMDD) (2-4). The etiology of PMS is still largely unknown and a set of complex and multi-dimensional factors may be involved. The role of ovarian hormones in PMS is unclear, but symptoms often improve when ovulation is suppressed. B6 is well known as the first-line treatment for premenstrual syndrome (PMS) (5-7). However, peripheral neuropathy of pyridoxine is characterized at doses greater than $200 \mathrm{mg} /$ day. Therefore, some researches are interested in herbal medicines such as Vitex agnus-castus and and Hypericum perforatum with lower dose of vitamin B6.

\section{Objectives}

The current study aimed to compare the positive and adverse effects of $H$. perforutum and vitamin B6 on premenstrual syndrome.

\section{Methods}

A double-blind, randomized controlled clinical trial (RCT) was conducted to determine the effects of $H$. perforatum and vitamin B6 on PMS. The protocols of the study were approved by the ethical review board and the dean of faculty, the deputy of educational affairs, and the educational affairs administration of Shiraz University. Parts of these findings were published as partial and brief communications (8). The study was conducted from April 2009 to March 2010 in the gynecology clinic of Zeinabieh Hospital affiliated to Shiraz University of Medical Sciences. The present study consisted of three phases of screening, preparation and treatment.

In the screening phase, participants were assessed in terms of eligibility. Inclusion criteria were 1) Female aged 
18 - 45 years and 2) Self-reported premenstrual syndrome symptoms for over six months. Females with psychiatric and health problems, psychotropic drug consumption, alternative treatment for PMS, known or planned pregnancy, lactating females and those who did not use any effective contraception or had irregular menstrual were excluded. Subjects who met these criteria filled out the informed consent form and were included in the study (8). A sample size included in the screening phase of this study. To determine the sample size of the preparation phase, data from a previous intervention study were used. A sample size of 78 subjects was estimated for each group. Furthermore, to compensate an expected dropout rate, the sample size was increased to 90 subjects in each group.

In the untreated parathion phase, the participants were asked to record their symptoms daily on a menstrual diary MD for two menstrual cycles before entering the treatment phase. The MD consisted of the following 12 symptoms: mood swing, anxiety, nervous tension or irritability, breast tenderness, swelling of extremities or weight gain, depression, crying, lack of concentration, insomnia, big appetite, headache and fatigue. It was also rated on a scale of one (not at all) to six (extreme). After screening and preparation phases (PP), 251 females were included in the treatment phase (TP), who were then randomly divided into three study groups, i e, perforan group ( $\mathrm{n}=85)$, the vitamin B6 $(\mathrm{n}=81)$ and the control $(\mathrm{n}=85)$.

The daily dose consisted of two $550 \mathrm{mg}$ tablets standardized to $330 \mu \mathrm{g}$ hypericin in $H$. perforutum group, two placebo tablets per day (containing lactose and cellulose) and two vitamin B6 tablets containing $80 \mathrm{mg}$ vitamin.

All participants were asked to complete MD questionnaires prospectively during the intervention cycles. At the end of two cycles, the questionnaires were collected and analyzed. Statistical analyses were performed by SPSS ver. 15.0 (SPSS, Chicago, IL, USA). Paired and independent samples T-tests were used to compare means within and between the groups, respectively. All tests were two-sided with a significance level of $\mathrm{P}<0.05$.

\section{Results}

According to the results of ANOVA test, demographic data such as age $(\mathrm{P}=0.580)$, height $(\mathrm{P}=0.834)$, weight ( $\mathrm{P}$ $=0.393)$ and age of menarche $(0.084)$ were not similar in all three groups at the baseline. The mean total score decreased from $34.47 \pm 6.82$ to $20.68 \pm 5.72$ (40\%) in the perforan group, from $33.93 \pm 6.95$ to $20.92 \pm 5.26$ (38\%) in the vitamin B6 group and from $33.86 \pm 6.16$ to $23.90 \pm 6(29 \%)$ in the control group. The mean total score demonstrated a statistically significant drop in the three arms compared to the baseline $(\mathrm{P}<0.001)$. Also, a comparison of the three groups showed a statistically significant difference at the terminal weeks $(\mathrm{P}<0.002)$. In fact, both groups under study showed a significant decline compared to the control group $(\mathrm{P}<0.005)$ (Table 1$)$

\subsection{Adverse Events \\ 4.1.1. Adverse Events Leading to the Dropout}

Patients were asked to report adverse effects using a post-trial questionnaire. The number of subjects who dropped out of the study due to adverse events was greater in the H. perforatum $(\mathrm{n}=8)$ compared to the vitamin $\mathrm{B} 6(\mathrm{n}=$ 3 ) and control groups $(n=4)$. However, no serious adverse events were reported (Table 2 ).

\subsubsection{Adverse Events not Leading to Dropout}

The most commonly reported adverse events were related to headache $(n=8)$ and nausea $(n=6)$ in H.perforatum and headache $(n=9)$ and dizziness $(n=5)$ in the vitamin B6 group. The three groups were not significantly different in this regard (Table 2 ).

\section{Discussion}

Based on the literature, the current study demonstrated the beneficial effect of vitamin b6 and H.perforutum on alleviating the premenstrual syndrome symptoms.

The effect of vitamin B6 on premenstrual syndrome was shown in several systematic reviews (9-12); therefore, the current study performed a comprehensive literature review regarding the effect of $H$. perforutum on premenstrual syndrome. In the first study, Stevinson et al. (13) performed a pilot study on 19 females with premenstrual syndrome. The patients received 900 mcg hypericin and a gradual decrease was observed in the mean total score of premenstrual syndrome (128.42 $\pm 68.15,70.11 \pm 46.10$ and $57.63 \pm 42.74$ ) during the baseline, cycle 1 and cycle 2. A significant decline was observed between the baseline and both cycle 1 and cycle 2 in all subgroups of premenstrual syndrome (subgroups are mentioned in However, However, there was a significant difference between cycle 1 and 2 in terms of premenstrual syndrome subscales such as out of control and breast tenderness. There were 12 shared symptoms in the current study and that of Stevinson et al. A comparison of two studies regarding the percentage of improvement is shown in Table 3. As indicated, almost all symptoms showed more improvement in the study by Stevinson et al. compared to the current study. However, some of these differences may be due to the lower dose of hypericin in the current study (660 vs. $900 \mathrm{mcg}$ ).

In the second trial by Hicks et al. (14), one hundred sixty nine females who met the inclusion criteria of patients 
Table 1. Premenstrual Daily Symptom Ratings Subscale and Individual Symptoms ${ }^{\mathrm{a}}$

\begin{tabular}{|c|c|c|c|c|c|c|c|}
\hline \multirow[t]{2}{*}{ Variables } & \multicolumn{2}{|c|}{ Perforan Group, $n=79$} & \multicolumn{2}{|c|}{ Vitamin B6 Group, $n=78$} & \multicolumn{2}{|c|}{ Control Group, $n=78$} & \multirow[t]{2}{*}{ PValue } \\
\hline & Baseline & Termination & Baseline & Termination & Baseline & Termination & \\
\hline Anxiety & $41.15 \pm 9.74$ & $23.08 \pm 14.78$ & $39.52 \pm 9.09$ & $25.79 \pm 7.89$ & $39.52 \pm 9.9$ & $25.27 \pm 7.89$ & 0.437 \\
\hline Depression & $29.26 \pm 7.49$ & $13.82 \pm 6.48$ & $28.33 \pm 8.1$ & $19.55 \pm 9.97$ & $28.33 \pm 8.1$ & $19.55 \pm 9.97$ & 0.001 \\
\hline Craving & $29.46 \pm 8.73$ & $17.26 \pm 7.41$ & $28.64 \pm 7.8$ & $20.60 \pm 7.77$ & $29.96 \pm 8.06$ & $22.62 \pm 6.4$ & 0.001 \\
\hline Hydration & $36.1 \pm 8.50$ & $26.10 \pm 10.18$ & $37.54 \pm 10.60$ & $16.62 \pm 9.67$ & $37.65 \pm 12.25$ & $28.35 \pm 13.22$ & 0.001 \\
\hline Total & $34.47 \pm 6.82$ & $20.68 \pm 5.72$ & $33.93 \pm 6.95$ & $20.92 \pm 5.26$ & $33.86 \pm 6.16$ & $23.90 \pm 6$ & 0.001 \\
\hline
\end{tabular}

${ }^{\mathrm{a}}$ Date presented as mean (SD).

Table 2. Addvers Effects Recorded at any Time in the Three Groups During the Intervention

\begin{tabular}{|c|c|c|c|c|c|c|}
\hline & \multicolumn{2}{|c|}{ Hypericum perforutum Group } & \multicolumn{2}{|c|}{ Control Group } & \multicolumn{2}{|c|}{ Vitamin B6 Group } \\
\hline & \multicolumn{6}{|c|}{ Side-Effects Leading to Withdrawal } \\
\hline & First Month & Second Month & First Month & Second Month & First Month & Second Month \\
\hline Pain over eyes & & 1 & & & & \\
\hline Rashes & 1 & & & & & \\
\hline Breast tenderness & & & & 1 & & \\
\hline Nausea & 1 & 1 & 1 & & & \\
\hline Dry mouth & 1 & & & & & \\
\hline Dizziness & & & & & 1 & \\
\hline Loss of appetite & & & & & & 1 \\
\hline Headache & 1 & & & 1 & 1 & \\
\hline \multirow[t]{2}{*}{ Diarrhea } & & & 1 & & & \\
\hline & \multicolumn{6}{|c|}{ Side-Effects not Leading to Withdrawal } \\
\hline Rashes & 2 & 0 & 1 & 1 & 0 & 0 \\
\hline Constipation & 2 & 2 & 4 & 8 & 2 & 1 \\
\hline Nausea & 4 & 2 & 2 & 0 & 1 & 0 \\
\hline Loss of appetite & 0 & 0 & 0 & 0 & 1 & 0 \\
\hline Headache & 5 & 3 & 7 & 1 & 8 & 1 \\
\hline Dizziness & 1 & 3 & 4 & 2 & 4 & 1 \\
\hline Diarrhea & 3 & 1 & 5 & 3 & 5 & 2 \\
\hline
\end{tabular}

with premenstrual syndrome were selected and randomly assigned into two groups of $H$. perforatum ( $\mathrm{n}=87,1800 \mu \mathrm{g}$ of hypericin) and control ( $\mathrm{n}=82$, containing lactose and cellulose). The $H$. perforatum group demonstrated more beneficial effects compared to the control group (though it was not significant). However, they attributed the insignificance of findings to insufficient statistical power of their study rather than the lack of efficacy of H. perforatum.

In the third trial, Canning et al. (15) conducted a double-blind, randomized and cross-over study. According to the results of ANOVA test, premenstrual syndrome decreased significantly in the two subgroups of premenstrual syndrome, i e, behavioral and physical $(\mathrm{P}<0.05)$, but no significant effect on mood and pain was observed $(\mathrm{P}>$ 0.05).

Two randomized controlled trials were found in Iranian database.

Salehi et al. (16) compared three groups of Vitex agnuscastus, $H$. perforatum and vitamin $\mathrm{E}$. The total mean score decreased from $62 \pm 31$ to $38 \pm 12$ in the H.perforatum (38\%), from $61 \pm 30$ to $25 \pm 17$ (59\%) in the Vitex agnus-castus group and from $61 \pm 32$ to $54 \pm 19$ (11\%) in the control group. 
Table 3. Comparison Between the Current Study and the Study by Stevinson et al. Regarding Percentage of Improvement

\begin{tabular}{|lcc}
\hline Symptoms & Current Study & Stevinson et al. s \\
\hline Anxiety & 39 & 63 \\
\hline Nervous tension or irritability & 35 & 59 \\
\hline Mood swings & 48 & 55 \\
\hline Depression & 52 & 80 \\
\hline Poor concentration & 50 & 66 \\
\hline Crying & 71 & 92 \\
\hline Insomnia & 46 & 39 \\
\hline Headache & 47 & 36 \\
\hline Increased appetite & 43 & \\
\hline Fatigue & 35 & 37 \\
\hline Breast tenderness & 21 & 50 \\
\hline Swelling of extremities or weight & 31 & 35 \\
\hline gain & & \\
\hline
\end{tabular}

Both the Vitex $(\mathrm{P}<0.001)$ and H. perforatum $(\mathrm{P}<0.005)$ groups showed a significant improvement compared to the vitamin E group. Also, Vitex group (59\%) was more efficient than the H. perforatum group (38\%).

Pakgohar et al. (17) compared two groups of H. perforatum and control. The premenstrual syndrome subscale psyclogica demonstrated a decreasing trend in the $H$. perforatum (54\%) and control group (17.5\%), which was statistically significant $(\mathrm{P}=0.005)$. The result of t-test demonstrated significant improvements with respect to physical subscale of the premenstrual syndrome in $H$. perforatum group (49\%) compared to the control group (21\%), which was statistically significant $(\mathrm{P}<0.001)$. To sum up, it seems that $H$. perforatum is effective in premenstrual syndrome relief.

Only one study was found in the literature that had compared vitamin B6 and H. perforatum. Sabet-Birjandi et al. (18) divided premenstrual syndrome into two subscales psychological and physical and showed that H. perforatum was more effective than vitamin B6 to mitigate the symptoms related to psychological and physical subscales, but the two groups were significantly different only in terms of psychological subscale $(\mathrm{P}=0.003)$ which was consistent with the current study results. The higher effectiveness of vitamin $\mathrm{B} 6$ and $H$. perforatum in terms of psychological and physical subscales in the current study compared to the study by Sabet-Birjandi et al. may be due to the larger study population and sample size of the current study. Previous studies (19) showed a significant relationship between the severity and prevalence of premenstrual symptoms and the consumption of sweet food such as cakes, deserts and chocolates. As a matter of fact, the youths who consumed more chocolate, caffeine and sweets were more prone to severe symptoms.

\subsection{The Effect of Vitamin B6 on Premenstrual Syndrome}

A review study included nine randomized, controlled trials, suggesting that pyridoxine (vitamin B6) supplement improved premenstrual (9). Consistent with the review systematic and meta-analysis (9-12), the current study showed the positive effects of vitamins on premenstrual syndrome. Adverse events were reported in five studies. Thirty-five adverse events were reported in Canning's study (15), 15 in the H. perforatum group and 20 in the control group, which comparison of the two groups was not significant. The most common adverse effect was digestive and respiratory symptoms, which was equally distributed between the two groups. One serious adverse event (chest pain) was reported, which was later found to be unrelated to H.perforatum. Six patients were dropped out in the study by Hicks et al. (14). Although dropout due to side-effects was more common in the H. perforatum $(\mathrm{n}=7)$ compared to the control group $(\mathrm{n}=1)$, no serious adverse events were observed in the $H$. perforatum group. As for the mild side effects not leading to the dropout, a similar rate was observed between the groups. In the study by Stevinson et al. (13), five females reported nausea, constipation, flatulence, dizziness and heavy menstrual. However, all symptoms disappeared after the treatment. Pakgohar et al. (17) reported no adverse effects, but in the study by Sabet-Birjandi et al. (18), six females reported adverse effects, one related to $H$. perforatum (rash skin) and five related to vitamin B6 (spotting). In the current study, the number of dropouts in the control was greater than that of the H. perforatum group, though the two groups were not significantly different. In general, there is a paucity of trials studying the safety of long-term consumption of $H$. perforatum but no serious adverse effects are reported on the short-term use of $H$. perforatum (Table 2).

A review study included nine randomized, controlled trials, suggesting that pyridoxine (vitamin B6) supplement improved premenstrual (9). Consistent with the systematic review and meta-analysis (9-12), the current study showed the positive effects of vitamins on premenstrual syndrome. Statistically significant changes are required to assess the meaningful improvement, but it is not sufficient. It is important to note clinically significant, especially medicine and psychology, defined as treatment satisfaction. The current study trials showed a statistically significant effect in both intervention groups (vitamin B6 and $H$. perforatum) compared to the control, but it is unclear whether they were clinically significant. Further trials are needed to study clinical and statistical effects 
Table 4. Comparison Between the Current Study and Other Studies on Adverse Effects

\begin{tabular}{|c|c|c|}
\hline \multirow{2}{*}{$\begin{array}{l}\text { Study } \\
\text { Current Study (330 } \mu \text { g Hypericin) }\end{array}$} & \multicolumn{2}{|c|}{ Detail } \\
\hline & $\begin{array}{l}\text { Pain Over Eyes }(n=1) \text {, rashes }(n=1) \text {, nausea }(n=2) \text {, dry } \\
\text { month }(n=1) \text {, headache }(n=1) \text {, constipation }(n=4) \text {, } \\
\text { nausea }(n=6) \text {, diarrhea }(n=4)\end{array}$ & $\begin{array}{l}\text { Side-effects not leading to withdrawal rashes }(n=2) \text {, } \\
\text { constipation }(n=4) \text {, nausea }(n=6) \text {, headache }(n=8) \text {, } \\
\text { dizziness }(n=4) \text {, diarrhea }(n=\end{array}$ \\
\hline Hicks et al., (1800 $\mu \mathrm{g}$ of Hypericin) & $\begin{array}{l}\text { Nausea, diarrhea, dry mouth }(n=1) \text { tiredness, } \\
\text { forgetfulness, woolly head }(n=1) \text {, headache, pain over } \\
\text { eyes }(n=1) \text {, nausea, worsening of premenstrual } \\
\text { symptoms }(n=1) \text {, bloatedness, breast tenderness, } \\
\text { rashes, sensitivity in right eye }(n=1)\end{array}$ & $\begin{array}{l}\text { Side-effects not leading to withdrawal nausea }(n=8) \\
\text { diarrhea }(n=6) \text { flatulence }(n=5) \text { headache }(n=13) \text { skin } \\
\text { rash }(n=3) \text { dizziness/confusion }(n=4) \\
\text { tiredness/sedation }(n=5)\end{array}$ \\
\hline Canning et al., (Standardized to 0.18\% Hypericin) & $\begin{array}{l}\text { Digestive (stomach cramps, abdominal pain, nausea, } \\
\text { diarrhea, dizziness) }(n=4) \text {, vasomotor (hot flushes, } \\
\text { increasedsweating) }(n=2) \text {, respiratory (cold, sinus } \\
\text { ache, sore throat, swollen glands, viral infection, } \\
\text { laryngitis) }(n=3) \text { headache/migraine }(n=1) \text {, spots }(n= \\
\text { 1), vaginal discharge }(n=1) \text {, menstrual flooding }(n=1) \text {, } \\
\text { forgetfulness }(n=1) \text {, chest pains }\end{array}$ & \\
\hline Canning et al., (Standardized to 0.18\% Hypericin) & $\begin{array}{l}\text { Five females reported nausea, constipation, flatulence, } \\
\text { dizziness, heavy menstrual. However, with continued } \\
\text { treatment, all symptoms were disappeared }\end{array}$ & \\
\hline Stevinson et al. (900 pg Hypericin/2 Cycle) & No adverse effect & \\
\hline Sabet-Birjandi et al. (990 pg Hypericin) & Hypericum perforatum (skin rash $\mathrm{n}=1$ ) & \\
\hline
\end{tabular}

\subsection{Conclusion}

Overall, compared to the chemical substances used in medications, Vitamin B6 and H. perforatum offer safe, welltolerated and effective drugs to treat Iranian females with moderate to severe PMS in Iran. According to the study findings, health professionals may recommend vitamin B6 and $H$. perforatum as a reasonable alternative to treat premenstrual syndrome.

\section{Acknowledgments}

\section{No Acknowledgements}

\section{Footnote}

Conflict of Interest: There was no conflict of interests regarding the material and results of the current study.

\section{References}

1. Freeman EW. Premenstrual syndrome and premenstrual dysphoric disorder: definitions and diagnosis. Psychoneuroendocrinology. 2003;28 Suppl 3:25-37. [PubMed: 12892988].

2. Halbreich U, Borenstein J, Pearlstein T, Kahn LS. The prevalence, impairment, impact, and burden of premenstrual dysphoric disorder (PMS/PMDD). Psychoneuroendocrinology. 2003;28 Suppl 3:1-23. [PubMed: 12892987].

3. Atmaca M, Kumru S, Tezcan E. Fluoxetine versus Vitex agnus castus extract in the treatment of premenstrual dysphoric disorder. Hum Psychopharmacol. 2003;18(3):191-5. doi: 10.1002/hup.470. [PubMed: 12672170].
4. Fathizadeh N, Ebrahimi E, Valiani M, Tavakoli N, Yar MH. Evaluating the effect of magnesium and magnesium plus vitamin B6 supplement on the severity of premenstrual syndrome. Iran J Nurs Midwifery Res. 2010;15(Suppl 1):401-5. [PubMed: 22069417].

5. Braverman PK. Premenstrual syndrome and premenstrual dysphoric disorder. J Pediatr Adolesc Gynecol. 2007;20(1):3-12. doi: 10.1016/j.jpag.2006.10.007. [PubMed: 17289510].

6. Curtis MG, Overholt S, Hopkins MP. Glass' office gynecology. Philadelphia: Lippincott Williams \& Wilkins; 2006.

7. Mortola JF. Premenstrual syndrome-pathophysiologic considerations. N Engl J Med. 1998;338(4):256-7. doi: 10.1056/NEJM199801223380409. [PubMed: 9435333]

8. Ghazanfarpour M, Kaviani M, Asadi N, Ghaffarpasand F, Ziyadlou S, Tabatabaee HR, et al. Hypericum perforatum for the treatment of premenstrual syndrome. Int J Gynaecol Obstet. 2011;113(1):84-5. doi: 10.1016/j.ijgo.2010.11.007. [PubMed: 21315349].

9. Wyatt KM, Dimmock PW, Jones PW, Shaughn O'Brien PM. Efficacy of vitamin B-6 in the treatment of premenstrual syndrome: systematic review. BMJ. 1999;318(7195):1375-81. [PubMed: 10334745].

10. Whelan AM, Jurgens TM, Naylor H. Herbs, vitamins and minerals in the treatment of premenstrual syndrome: a systematic review. Can J Clin Pharmacol. 2009;16(3):407-29. [PubMed: 19923637].

11. Williams AL, Cotter A, Sabina A, Girard C, Goodman J, Katz DL. The role for vitamin B-6 as treatment for depression: a systematic review. Fam Pract. 2005;22(5):532-7. doi: 10.1093/fampra/cmi040. [PubMed: 15964874].

12. Wyatt $K$, Dimmock P, Jones P. Poor-quality studies suggest that vitamin $\mathrm{B}(6)$ use is beneficial in premenstrual syndrome. West J Med. 2000;172(4):245. [PubMed: 18751259].

13. Stevinson C, Ernst E. A pilot study of Hypericum perforatum for the treatment of premenstrual syndrome. BJOG. 2000;107(7):870-6. [PubMed: 10901558].

14. Hicks SM, Walker AF, Gallagher J, Middleton RW, Wright J. The significance of "nonsignificance" in randomized controlled studies: a discussion inspired by a double-blinded study on St. John's wort (Hypericum perforatum $\mathrm{L}$.) for premenstrual symptoms. J Altern Complement Med. 2004;10(6):925-32. doi: 10.1089/acm.2004.10.925. [PubMed: 15673985]. 
15. Canning S, Waterman M, Orsi N, Ayres J, Simpson N, Dye L. The efficacy of Hypericum perforatum (St John's wort) for the treatment of premenstrual syndrome: a randomized, double-blind, placebocontrolled trial. CNS Drugs. 2010;24(3):207-25. doi: 10.2165/11530120000000000-00000. [PubMed: 20155996].

16. Salehi A, Momeni H, Seraji A. Comparison of the effects of Hypericum and Vitex agnus premenstrual syndrome compared with vitamin E: a randomized clinical trial. 2013

17. Pakgohar M, Mehran A, Salehi Sour Moghi M, Akhondzadeh S, Ahmadi M. Comparison of hypericum perforatum and placebo in treatment of physical symptoms of premenstrual syndrome. Hayat 2004;10(3):31-7.

18. Sabet-Birjandi S, Tadayon-Najafabadi M, Siyahpooshan A, Haghighizadeh M. Comparision the effect of Hypericum perforatum and vitamin B6 in the treatment of premenstrual syndrome. Zahedan J Res Med Sci. 2011;13(4):1-5.

19. Rossignol AM, Bonnlander H. Prevalence and severity of the premenstrual syndrome. Effects of foods and beverages that are sweet or high in sugar content. J Reprod Med. 1991;36(2):131-6. [PubMed: 2010896]. 